\title{
Arbor
}

\section{En época del Medievo}

\author{
Joaquín $M^{a}$ Córdoba
}

Arbor CLXXX, 711-712 (Marzo-Abril 2005), 507-513 pp.

El siglo XIII y sobre todo los dos siguientes, el XIV y el XV, siglos que Johan Huizinga evocaría como "el otoño de la Edad Media»" , parecen haber sido especialmente fértiles en viajes a mundos remotos. Frailes y nobles, comerciantes y aventureros europeos unidos en épicas jornadas llegarían a regiones tan remotas como el corazón de Mongolia, el Mar Rojo o las islas de Java y Sumatra. Y entre las vidas, los viajes y los recuerdos de fray Guillermo de Rubruck, Marco Polo o Niccolò dei Conti, redescubrimos nosotros el valor y las aventuras de viajeros españoles que, como Ruy González de Clavijo o Don Pero Tafur, escribieron libros hoy estimados entre los mejores de aquel otoño primaveral, que acabaría con el amanecer de América y la inmensidad abierta del océano hallado al otro lado del cabo de Buena Esperanza.

Sin embargo, los inicios del siglo XIII nos parecen del todo opuestos a la experiencia viajera, con la caída de Jerusalén (1187) y la dramática reducción del reino latino de Oriente. Pero sucedió todo lo contrario. Peregrinos y comerciantes siguieron teniendo paso franco y además, la angustiosa búsqueda de aliados frente al Islam animarían viajes distintos a regiones mucho más remotas de Oriente, más allá de Mesopotamia y el Irán, en busca del Preste Juan². La noticia de que al otro lado del mundo musulmán existía un poderoso reino cristiano llegó a Occidente a mediados del siglo XII, al transmitirse un rumor propalado en Siria sobre la existencia de un rey cristiano, llamado Juan, que era preste y señor al tiempo de un imperio que estaba más allá de Persia ${ }^{3}$. Puede que la corrupción del título real de las estepas, «jan», transmitido de unos a otros, derivara en la leyenda de un rey Juan, que se creía -se necesitaba creercristiano. Desde 1150, primero el emperador de Constantinopla y luego el del Sacro Imperio y el Papa fueron recibiendo una carta de aquel rey y supuesto Preste $\mathrm{Juan}^{4}$, una falsificación interesada para animar la in- 
tervención. Pero la embajada enviada en 1177 por el Papa Alejandro III nunca regresó. Y poco a poco empezó a desvelarse la verdad.

Hacia el 1219, cuando en Europa empezaba a fraguarse el gran enfrentamiento entre el Papado y el emperador Federico II, Gyngis Jan comenzaba la conquista y destrucción del gran Sultanato de Jorezm ${ }^{5}$. La noticia corrió por Oriente a través de los cristianos nestorianos, ortodoxos y católicos, pero la ilusión en un aliado providencial se reveló vana, cuando los mongoles aplastaran a los cristianos del rey Jorge IV de Georgia (1221) y a los príncipes rusos el año siguiente. Y no mucho después, la gran Rusia de Kiev caería en la batalla del rio Sit (1238). La catástrofe que arrasó el brillo del primer gran estado ruso ${ }^{6}$ significaba también la aniquilación de un gran reino cristiano, tratado con una crueldad que destruía las esperanzas. En 1241 la caballería mongola entraba en Polonia, Hungría y Austria, y sólo la noticia de la muerte del Gran Jan Ogodai hizo que Batu se retirara con el ejército para luchar por la herencia. Lo dramático de la situación en Europa y Palestina movió al Papa Inocencio IV a enviar, en 1245, una misión encabezada por el franciscano fray Giovanni di Pian di Carpine ${ }^{7}$. Primer europeo en entrar en la corte de Karakorum -más allá del desierto de Gobi, en la remota región de los montes de Yangaï, junto al río Orjon-, su embajada no tuvo resultados, aunque le sirvió para escribir una Historia Mongalorum quos nos Tartaros appellamus, llena de curiosas observaciones sobre sus costumbres y su imperio, y para que otro fraile dictara un relato sucinto del viaje ${ }^{8}$.

Pero nuestra historia siguió su curso. En Occidente, Castilla y Aragón acababan la reconquista: Fernando III recuperaba casi toda Andalucía (1248), y Jaime II liberaba todo el Levante. Desde entonces, ambos reinos empezaron a mirar hacia el exterior: Alfonso X aspirando a la corona del Sacro Imperio, y Pedro III de Aragón conquistando Sicilia en 1282. Pronto, los comerciantes peninsulares navegarían por todas las rutas mediterráneas, y tras ellos habrían de llegar los peregrinos y los embajadores. Mientras tanto, entrada ya la segunda mitad del siglo XIII, la necesidad política iba a decidir curiosas amistades y viajes asombrosos. Cuando la Cruzada de San Luis fracasaba, el rey firmó una alianza con los asesinos y su Maestre de Maysad, y en 1253, ante la supuesta conversión al cristianismo de un príncipe mongol, envió una embajada encabezada por el dominico fray Guillermo de Rubruck ${ }^{9}$. Como el trayecto por los reinos musulmanes parecía difícil, la misión navegó a Constantinopla y de allí a Crimea, parte entonces del imperio del Gran Jan. En el Volga alcanzó el campamento de Batu, y el 27 de diciembre del mismo año llegó a Karakorum, capital de Mongka. De sus entrevistas, observa- 


\section{En época del Medievo}

ciones y disputas teológicas sabemos gracias a su magnífico relato Itinerarium Willelmi de Rubruc ad partes orientales, que como escriben Cl.-C. y R. Kappler, no es una simple relación sino "todo un paisaje», que une su misma aventura con la historia, geografía, religión, costumbres halladas o las anécdotas vividas. Y tras un epopéyico viaje de vuelta de más de diez mil kilómetros, tras bordear el Mar Caspio y cruzar el Cáucaso y parte de Anatolia, llegó a Acre el 15 de agosto de 1255.

Es obvio que las embajadas eran de resultados cortos, porque los reinos cristianos de Europa parecían irrelevantes a los mongoles. Poco después de la embajada de fray Guillermo, el Gran Jan decidió la conquista de China y del Oriente islámico. Mientras él se orientaba al este, su hermano Hulagu entró en Irán, acabó con la secta ismaelita y sus fortalezas y, en 1258, arrasó Bagdad poniendo así fin al califato ${ }^{10}$. La caída de los "asesinos» alegró a todos, pero la muerte del último Califa y la feroz destrucción de Bagdad llenó de consternación al mundo islámico. Cuando en 1260 las tropas mongolas entraron en Aleppo y Damasco, y en esta última unidos Bohemundo de Antioquía, Het'um de Armenia y el general cristiano nestoriano de Hulagu Kitbuqa, parecía que el sueño nacido con la leyenda del Preste Juan estaba a punto de cumplirse ${ }^{11}$. Pero contra lo que podría esperarse, las autoridades cruzadas prefirieron apoyar al sultán mameluco -posiblemente por presiones e inconfesables intereses de los venecianos-, y a comienzos de septiembre del mismo año, cuando Hulagu había abandonado Siria a causa de la muerte del jan, su general Kitbuqa fue derrotado en la batalla de Aïn Yaluf. Con la victoria mameluca quedaba sellado el destino de los reinos latinos.

Luego y sucesivamente, el nuevo Gran Jan Kubilai se orientó hacia China, los mongoles de Irán se islamizaron y los reinos cristianos se extinguieron para siempre con la caída de Acre el 18 de mayo de 1291. Pero antes, Marco Polo había abierto todavía más el mundo conocido con su viaje hacia la corte de Kubilai en Pekín (1271), durante el cual cruzó Armenia, el Irán mongol, el Pamir, las estribaciones meridionales del desierto de Taklamakán y ya por China, hasta el Ordos y Pekín. De su viaje, de los casi veinte años que allí residió y de la remota China de Kubilai se sabría gracias a su famoso libro Il Milione, dictado hacia 1298 a Rustichello de Pisa ${ }^{12}$.

Ya entrado el siglo XIV, Oriente y Occidente iniciaron una nueva etapa. La Guerra de los 100 años consumiría las energías de una buena parte del continente europeo, mientras que los reinos peninsulares remataban la reconquista y miraban más allá de sus costas. En 1340, Alfonso XI aplastó a los benimerines en la Batalla del Salado y encerró al 
residual reino de Granada dentro de fronteras limitadas: Portugal y Castilla comenzaron a navegar por el Atlántico -en 1344 el Papa donó las Islas Canarias a Don Luis de la Cerda ${ }^{13}$ - y Aragón, que ya dominaba Sicilia desde 1282, obtuvo en 1324 Cerdeña, y en 1381 el Ducado de Atenas. Pero todavía, y durante todo aquel siglo, los viajeros europeos siguieron siendo fundamentalmente italianos, como fray Odorico da Pordenone, que en 1318 inició un largo viaje hasta China-donde residió muchos años-, y a la vuelta del cual escribió un relato que alcanzó cierta fortuna pese a su sequedad descriptiva ${ }^{14}$. Tras atravesar Mesopotamia y Persia, le corresponde a él la primera mención conocida de las ruinas y ciudad de Persépolis, aunque la llamara Comerum, ignorando su antigua y verdadera estirpe. Más tarde, Benedicto XII enviaría al franciscano Giovanni de Marignolle como embajador a la corte del Gran Jan en Pekín. Salió de Aviñón en diciembre del 1338, pero sólo pudo retornar a Europa en 1353. Por encargo del emperador Carlos IV escribió una Crónica de Bohemia, en la que incluyó la historia de su viaje de ida y vuelta, describiendo al paso sitios y monumentos tales como la que llama "torre de Nembrot» (sic), probablemente y tras la de Benjamín de Tudela, una nueva mención a las ruinas de Birs Nimrud ${ }^{15}$. Notables fueron tambien en el siglo XIV la vida y viajes de Ibn Batțūta, el célebre viajero tangerino, que sería autor de una monumental rih̆la, género literario fundado por Ibn Ŷubair ${ }^{16}$, en el que narraba sus legendarios viajes por sitios tan distantes como Egipto, Siria, Arabia, las costas africanas, Anatolia, Asia Central, Irán, India y China. Pero claro está, el manuscrito árabe sería poco conocido en el Occidente cristiano, lo que no ocurriría con un libro escrito en francés por un tal Sir John Mandeville, autor en realidad de un relato escrito a partir de otros documentos, con los que el autor se atrevía a narrar un supuesto viaje por Oriente Próximo, Egipto, Etiopía, India, Mongolia y China ${ }^{17}$.

Con el siglo XV, aquel "otoño de la Edad Media» que al principio evocábamos, desembocaría en la primavera de una nueva época. Naturalmente, en Oriente se revelaban nuevos peligros con el alud de los turcos, que tras ocupar Anatolia entraron en los Balcanes dejando aislado al agónico Imperio Bizatino. La implicación castellana en la escena internacional hizo que Enrique III enviara embajadas a Tamerlán, nuevo jan de los mongoles. La primera, compuesta por los nobles Payo Gómez de Sotomayor y Hernán Sánchez de Palazuelos, asistiría asombrada a la gigantesca batalla de Angora de 1402, donde Tamerlán venció, muriendo el sultán Bayaceto ${ }^{18}$. La segunda, fruto obligado de este contacto y del mutuo interés de Tamerlán y Enrique III, la embajada de Ruy González 
de Clavijo, en quien hoy reconocemos a uno de los más grandes viajeros, autor de un libro excelente. En aquel siglo, los venecianos seguían comerciando por todas las rutas, como Niccolò dei Conti, viajero que había de recorrer regiones inmensas, pasando por Siria, Mesopotamia, el Golfo Pérsico, la India, China, Java, Sumatra, Ceylán, las costas del Mar Rojo y Egipto ${ }^{19}$, y con el que en su retorno, uno de nuestros grandes viajeros, el noble peregrino Don Pero Tafur, mantuvo un encuentro de todo punto asombroso.

El siglo estaba acabando cuando el embajador Giosafat Barbaro fue enviado a Irán en 1473, en busca de alianzas contra los turcos, iniciando un viaje en el que tendría ocasión de visitar y describir escuetamente las ruinas de Persépolis, Naqs-i Rustán y Pasargada ${ }^{20}$. Pero más importante para la historia del mundo sería sin duda la asombrosa misión secreta encomendada por Juan II de Portugal a Pedro de Covilhao: averiguar si realmente se podía llegar a la India caboteando las costas del continente africano. Partió en 1487, por Egipto y el Mar Rojo alcanzó el Oceano Índico y la India, haciéndose pasar por un comerciante musulmán. Desde aquella fue a Ormuz, y aprovechando los Monzones navegó hasta Mozambique, conociendo allí la certeza de la navegación en torno a África. Vuelto a El Cairo envió a Portugal tan valiosa información $^{21}$, pero quiso la fortuna que a fines de enero del año 1488, Bartolomé Dias doblara el Cabo de Buena Esperanza, y aunque los marinos no volvieran a Lisboa hasta diciembre del mismo año, el mensaje de Covilhao llegaría sólo en 1491. Con el suyo y otros más acababa también la leyenda del Preste Juan, pero a cambio los límites del mundo se abrían inabarcables.

\section{Notas}

1 Huizinga, J. (1979): El otoño de la Edad Media, Alianza Editorial, S. A., Madrid.

2 Gumilev, L. N. (1994): La busca de un reino imaginario. La leyenda del Preste Juan. Ediciones Crítica, Grijalbo-Mondadori, Barcelona.

3 Es muy probable que la leyenda naciera en 1141, cuando un jan del reino Kara Jitai, medio budista, medio nestoriano, que se extendía al este del Syr Daria y al sur del lago Balkach, aplastara en la batalla de Katwan a los turcos selyúcidas musulmanes. Sobre los kara jitai ver Roux J.-P. (1997) : L'Asie Centrale. Histoire et civilisations, Librairie Arthème Fayard, Paris, pp. 260-264. La llegada del rumor al Oriente latino puede seguirse en Runciman, S. (1973) : Historia de las Cruzadas, Alianza Editorial, S. A., Madrid, volumen II, p. 229.

${ }^{4}$ GIL, J. (1993): En demanda del Gran Khan. Viajes a Mongolia en el siglo XIII. Alianza Editorial, S. A., Madrid, pp. 29-31.Véase igualmente RunCIMAN, S. (1973): Historia de las Cruzadas. Alianza Editorial, S. A., Madrid, volumen II, p. 382. 
5 Morgan, D. (1990): Los mongoles, Alianza Editoral, S. A., Madrid, pp. 91-93. Runciman, S. (1973): op. cit., volumen. III, pp. 228-231. Grousset, R. (1991): El Imperio de las Estepas. Atila, Gengis Kan, Tamerlán. Editorial EDAF, S. A., Madrid., pp. 277-285.

6 No hay demasiados estudios sobre la cultura y la historia de la Rusia del Principado de Kiev, fuera de la bibliografía estrictamente rusa. Para un estudio histórico detenido del periodo y un análisis detallado de la brillante cultura de la región entre los siglos IX y XIII véase DonNerT, E. (1983): Das Kiever Russland. Kultur und Geistesleben vom 9. bis zum beginnenden 13. Jharhundert. Urania-Verlag, Leipzig-Jena-Berlin. Sobre la campaña de los mongoles y su prolongación en la Europa Central véase también GrousSET, R. (1991), op. cit., pp. 306-310.

7 GIL, J. (1993): op. cit., p. 70.

8 La Historia Mongalorum (sic), de Giovanni di Pian di Carpine la traduce Juan Gil en su op. cit. pp.159-249. La relación tomada a fray Benito de Polonia en pp.251-258.

9 GIL, J. (1993): op. cit., pp. 108-118. Su versión española del texto completo en pp. 281-449. Es muy notable también el estudio y versión francesa de KAPPLER, Cl.C. y R. (1997): Guillaume de Rubrouck. Voyage dans 'Empire Mongol, 1253-1255, Imprimerie nationale Éditions, Paris, con magníficas fotografías de Roland Michaud. Interesantes observaciones sobre el viaje y los mongoles en GroussET, R. (1991): op. cit., pp. 317-324.

10 Grousset, R. (1991): op. cit., sobre la destrucción de los asesinos y el asedio y aniquilación de Bagdad, pp. 393-396. Sobre la ocupación de Siria y la derrota y muerte de Kitbuqa, pp. 399-405.

11 Morgan, D. (1990): op. cit., p. 182.

12 Sobre Marco Polo, sus viajes y y el mundo alrededor véase LARNER, J. (2001): Marco Polo y el descubrimiento del mundo, Ediciones Paidós Ibérica, S. A. Una buena versión española de su libro en ARMiÑo, M. (ed.) (1984): Marco Polo. Libro de las Maravillas, Ediciones Generales Anaya, S. A., Madrid.

13 LANDSTRÖM, B. (1971): En busca de las Indias. Editorial Juventud Barcelona, pp. 145-156. Sobre la intervención de Don Luis de la Cerda, véase FERnández-Armesto, F. (1993): Antes de Colón. Exploración y colonización desde el Mediterráneo hacia el Atlántico, 1229-1492. Ediciones Cátedra, S.A., Madrid, p. 189.

14 GuÉrin Dalle Mese, J. (ed.): 1990. Memoriale Toscano. Viaggio in India e Cina (1318-1330) di Odorico da Pordenone, A cura di Lucio Monaco. Edizioni Dell’Orso, Alessandria.

15 ErRera, C. (1934): Marignolli, fra Giovanni dei. En Enciclopedia Italiana di Scienze, Lettere ed Arti, Istituto della Enciclopedia Italiana Fondata da Giovanni Treccani, volumen XXII, Roma, p. 321.

16 FAnJUl, S. y ARBós, F. (eds.) (1987): Ibn Batṭūṭa. A través del Islam. Alianza Editorial, S. A., Madrid.

17 Delur, Ch. (ed.) (1993): Voyage autour de la terre de Sir John Mandeville, Les Belles Lettres, Paris.

18 Conde Mora, Fco. Gl. (2002): Payo Gómez de Sotomayor. Un noble gallego ante el gran Tamerlán. Historia 16, 315, pp. 111-118. Sobre la campaña de Tamerlán y la derrota de Bayaceto véase Grousset, R. (1991): op. cit., pp. 484-488.

19 Landström, B. (1971): op. cit., pp. 191-195. Y también SuRdich, F. (1983): Conti, Niccolo' de'. En Dizionario Biografico degli Italiani, Istituto della Enciclopedia Italiana fondata da G. Treccani, vol, 28, Roma, pp. 457-460. 


\section{En época del Medievo}

20 Almagià, R. (1964): Barbaro, Giosafat. En Dizionario Biografico degli Italiani, Istituto della Enciclopedia Italiana fondata da G. Treccani, ol. 6, Roma, pp. 106-109.

${ }^{21}$ LANDSTRÖM, B. (1971): op. cit. pp. 216-223. 